\title{
Size Distribution Estimation Method using Reflected Laser Light Angle Dependency by Rain Droplets
}

\author{
Kohei $\mathrm{Arai}^{1}$ \\ ${ }^{1}$ Graduate School of Science and Engineering \\ Saga University \\ Saga City, Japan
}

\begin{abstract}
Methods for size distribution estimation and rainfall type discrimination with estimated phase function using measured reflected laser light by rain droplet are proposed. Preliminary experiments are conducted with Laser ranging instrument and spectral radiometer for estimation of size distribution and rainfall type discrimination as well as phase function of scattering by rain drops. Through the experiments, it is found that rainfall type can be discriminated together with rain droplet size distribution estimation.
\end{abstract}

Keywords-Rainfall; Laser ranging; Marshall Palmer distribution; Rayleigh scattering; Mie scattering; Phase function; Rain drpolet size distribution

\section{INTRODUCTION}

Land slide detection and prediction due to heavy rain is important. Therefore, not so small number of systems are proposed so far. It requires quit high sensitivity of a tiny slide ( $\mathrm{mm}$ order) has to be detected for prediction. The proposed method ensures that such high sensitivity of a slide in the order of $\mathrm{mm}$. Landslide is one of severe disaster. In order to monitor landslides, several methods have been proposed so far. One of the conventional land slide monitoring systems is to measure the resistance of the wire which is set at potential landslide steeply slopes. Although it is simple and cheap system, measurement accuracy is not so good in terms of the distance between two ends of the wire which depends on resistance. Therefore, it cannot be used for making caution for evacuation from the potential landslide area. Other wide variety of commercial off-the-shelf electronic and/or mechanical geotechnical and hydrologic sensors exist [1],[2]. Meanwhile, satellite remote sensing imagery data is used for disaster relief due to landslide. It cannot be used for landslide warning system. There are so many previously proposed methods for detection of landslide areas such as differentiation with edge enhancing filters [3], texture feature extraction [4], vegetation index utilized land cover change detection method [5], 3D stereo pair of images utilized change detection method [6], etc. Also, satellite remote sensing based rainfall rate estimation methods are proposed and discussed [7]-[10].

It is well known that laser ranging instrument allows $\mathrm{mm}$ order of movement from several $10 \mathrm{~m}$ far from the target. It, however, is affected by rainfall. Rain droplet reflect and scattered the laser light. Therefore, previous system utilized time diversity method. Namely, if rain droplets are situated in between laser ranging instrument and the target, received signal returned faster than that without rain droplet. Therefore, the longest time duration between laser light emission and receiving the return signal from the target corresponds to the distance between laser ranging instrument and the target. Thus, influence due to rain droplets can be reduced. Although the sensor network for landslide monitoring with laser ranging system avoiding rainfall influence on laser ranging by means of time diversity and satellite imagery data based landslide disaster relief is proposed already, rainfall rate estimation accuracy is not good enough. Another demand for land slide monitoring is that rain type discrimination and rain droplet size distribution estimation. Droplet size and rainfall rate can be estimated. Thus, land slide detection and prediction can be done accurately.

The proposed methods for size distribution estimation and rainfall type discrimination using measured phase function make land slide detection and prediction accurately. If not only distance measurements but also observation angle dependency on the measured scattered laser light due to rain droplets is measured, then optical property, scattering characteristics of the rain droplets is estimated together with rain droplet size. Thus rain type can be estimated together with rainfall rate. The method proposed here is to estimate for both rain type and rainfall rate.

The next section describes the proposed system followed by experiment. The experiments can be divided into two are intended to show the sensitivity of solar direct and diffuse pointing angle on the aerosol parameter estimations. Then concluding remarks are described with some discussions.

\section{PROPOSED METHOD}

\section{A. Research Background}

F.Yoshino [11], Christian Matzler [12], and the others estimate parameters of droplet size distributions, stratiform (Marshall and Palmer), drizzling (Joss-Drizzle), thunderstorm (Joss-Thunderstorm) and realistic rainfall (Laws-Persons) by using Normalized distribution (Marshall-Palmer: MP, JossDrizzle: JD, Joss-Thunderstorm: JT and LP distributions). Typical parameters of these different types of rainfall are shown in Table 1. Droplet size distribution, on the other hand, is shown in Fig.1. 
TABLE I. PARAMETERS FOR LP, MP, JD, JT DISTRIBUTIONS

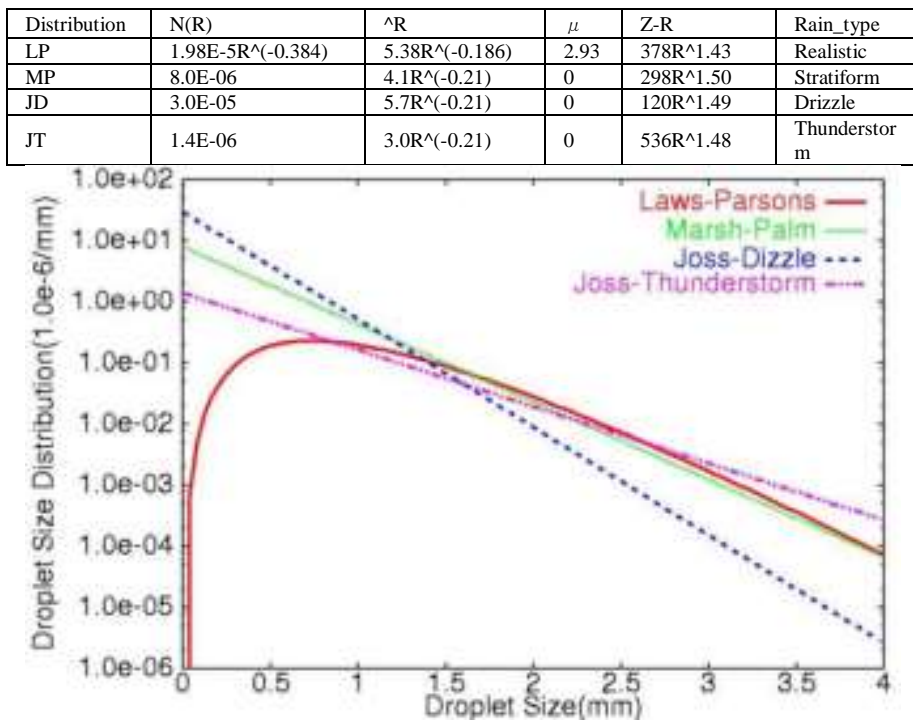

Fig. 1. Droplet size distribution of four typical rainfall models

$N(D)$ denotes droplet size distribution and is represented as equation (1) of gamma distribution function proposed by Ulbrich [13].

$$
N(D)=N_{0} \exp \left(-\Lambda D^{\mu}\right)
$$

where $N_{0}$ denotes $N$ axis cross section of droplet size distribution while $D$ denotes the factorial of power law of rain droplet size distribution. Meanwhile, $\mu$ denotes slope droplet size distribution in logarithmic-logarithmic expression. When $\mu=0$, then $\mathrm{D}^{\mu}=1$. On the other hand, $\Lambda$ defines exponential function based droplet size distribution,

$\Lambda=\alpha R^{\beta}$.

Furthermore,

$$
\begin{aligned}
& \Lambda=4.1 \times R^{-0.21}\left(\mathrm{~mm}^{-1}\right) \\
& N_{0}=8 \times 10^{3}\left(\mathrm{~mm}^{-1} \mathrm{~m}^{-3}\right)
\end{aligned}
$$

The parameters shown in Table 1 are estimated based on Rayleigh scattering assumption. Thunderstorm is characterized as relatively large "a" and comparatively small " $b$ " while stratiform is characterized as relatively small " $a$ " and comparatively large "b". These estimated results are coincident to Z-R Relation ${ }^{1}$ which is estimated by Remko Uijlenhoet et al. [14]. If we assume a certain drop size distribution (e.g., Marshall Palmer), the Z-R relation is for rain assuming a Marshal Palmer drop size distribution:

$$
\Lambda=200 R^{1.6}
$$

Next Mie scattering based Z-R Relation is estimated. In general, the number of droplets is decreasing in accordance with decreasing of droplet size [15]. From Fig.2, it is set that droplet size ranges from 1 to $6.4 \mathrm{~mm}$ while air temperature is assumed to be 20 degrees centigrade under the standard atmospheric pressure.

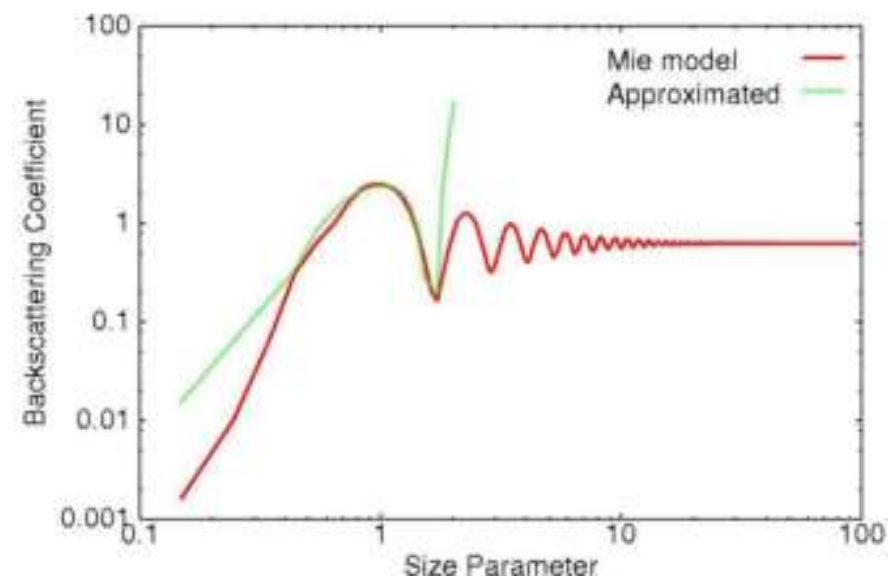

Fig. 2. Mie scattering based backscattering coefficient and its approximated coefficient

\section{B. Optical Property}

Optical property of scattered laser light by rain droplet depends on droplet size. If the droplet size is smaller than Rayleigh limitation $(\lambda / 10$ where $\lambda$ denotes observation wavelength), the optical property can be described by Rayleigh scattering theory. As shown in Fig.3, forward and backward scattering components are almost same.

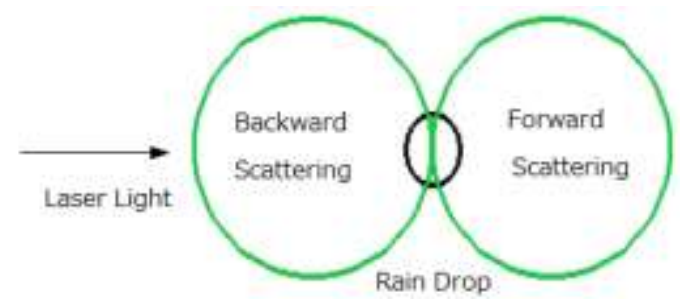

Fig. 3. Rayleigh scattering property

Therefore, phase function $P_{m}(\vartheta)$ of scattering property can be described as equation (5).

$$
P_{m}(\vartheta)=\left(\frac{3}{4}\right)\left(1+\cos ^{2} \vartheta\right)
$$

The Rayleigh scattering of phase function is illustrated in Fig.4. On the other hand, if the droplet size is greater than Rayleigh limitation, the optical property can be described by Mie scattering theory. As shown in Fig.5, forward scattering is dominant.

Mie scattering intensity is expressed as equation (6).

$$
\beta_{a}(\vartheta)=\frac{r^{2}}{2 \pi} \int_{r_{\min }}^{r_{\max }}\left\{i_{1}(\vartheta, x, \widetilde{m})+i_{2}(\vartheta, x, \widetilde{m})\right\} n(r) d r
$$

where $i_{1}, i_{2}$ denotes Mie scattering intensity function as the function of $x$ of size parameter, $\vartheta$, and $\widetilde{m}$ of rain droplet refractive index. On the other hand, $n(r)$ denotes the number of droplets of which the radius is $r$ and is called as number of droplet particle size distribution in unit of $1 / \mathrm{cm}^{2} / \mu \mathrm{m}$. 


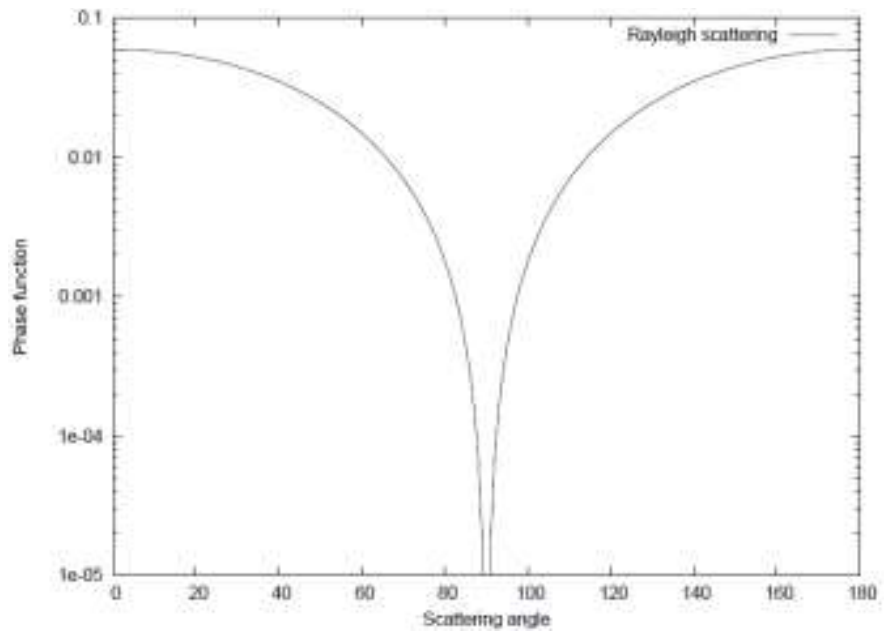

Fig. 4. Phase function of Rayleigh scattering property

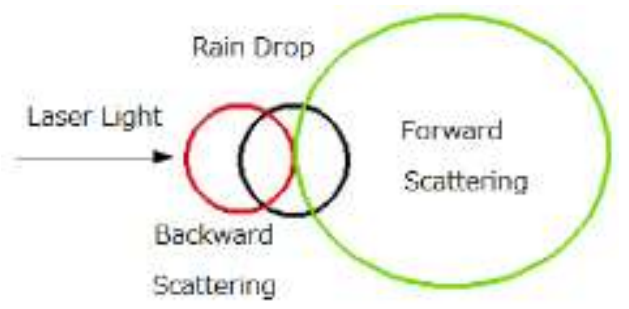

Fig. 5. Mie scattering property

$n(r)=d N(r) / d r$

The size parameter can be represented as follows,

$$
\mathrm{x}=\left(\frac{2 \pi}{\lambda}\right) r
$$

The Mie scattering of phase function is illustrated in Fig.6.

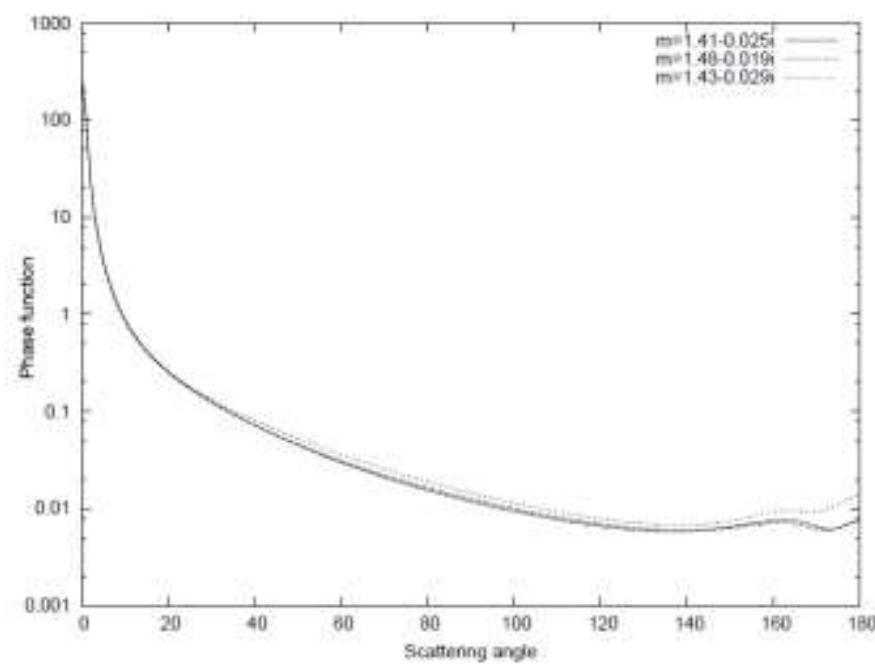

Fig. 6. Phase function of Mie scattering property

\section{Simulation}

For the proposed method, observation wavelength of laser light is much smaller than rain droplet size. Therefore, rain droplet scattering property can be described by Mie scattering theory. Using MODTRAN ${ }^{2}$ of software code of radiative transfer model, phase function can be calculated. Fig.7 shows the phase function for rainfall rate of 1, 5, 10 and $15 \mathrm{~mm} /$ hour.

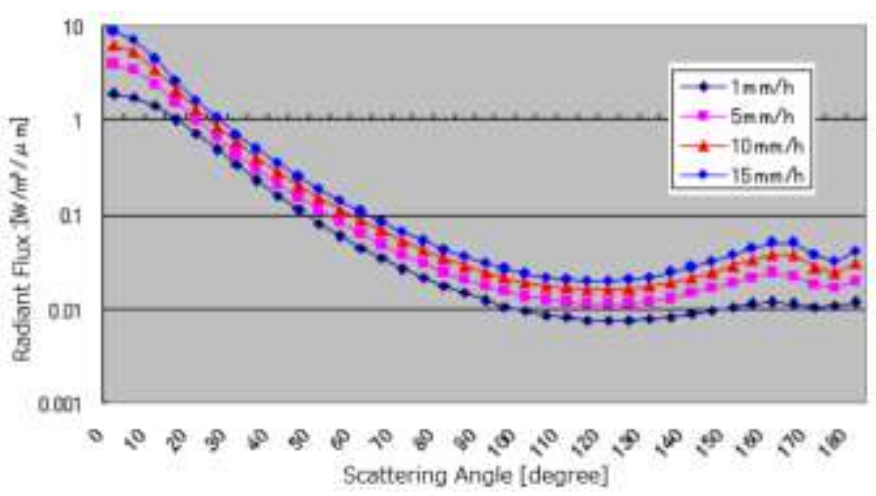

Fig. 7. Phase function of rain droplets

Therefore, it is possible to estimate rainfall rate using measured phase function. The phase function can be measured with reflected laser light intensity with the different observation angles.

\section{EXPERIMENTS}

\section{A. Preliminary Experiment}

The configuration of the preliminary experiment is illustrated in Fig.8.

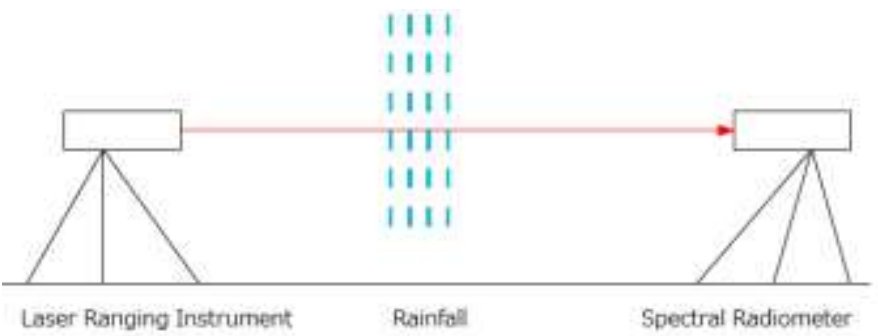

Fig. 8. Configuration of preliminary experiment

Outlook of the laser ranging instrument used is shown in Fig.9 (a) while that of the spectral radiometer is shown in Fig.10, respectively. Meanwhile, major specifications of the laser ranging instrument LEICA DISTO $\mathrm{A} 6^{3}$ and the spectral radiometer MS-720 are shown in Table 2 and 3, respectively.

TABLE II. MAJOR SPECIFICATION OF LASER RANGING INSTRUMENT OF LEICA DISTO A6

\begin{tabular}{|l|l|}
\hline Measurable_range & $0.05 \mathrm{~m} \sim 200 \mathrm{~m}$ \\
\hline Accuracy & $\pm 1.5 \mathrm{~mm}$ \\
\hline Laser_color & Red \\
\hline Laser_wavelength & $620-750 \mathrm{~nm}$ \\
\hline
\end{tabular}

\footnotetext{
${ }^{2}$ https://en.wikipedia.org/wiki/MODTRAN

${ }^{3}$ http://distagage.us/distoa6.html

${ }^{4}$ http://eko.co.jp/meteorology/met_products/0015.html
} 
TABLE III. MAJOR SPECIFICATION OF MS-720

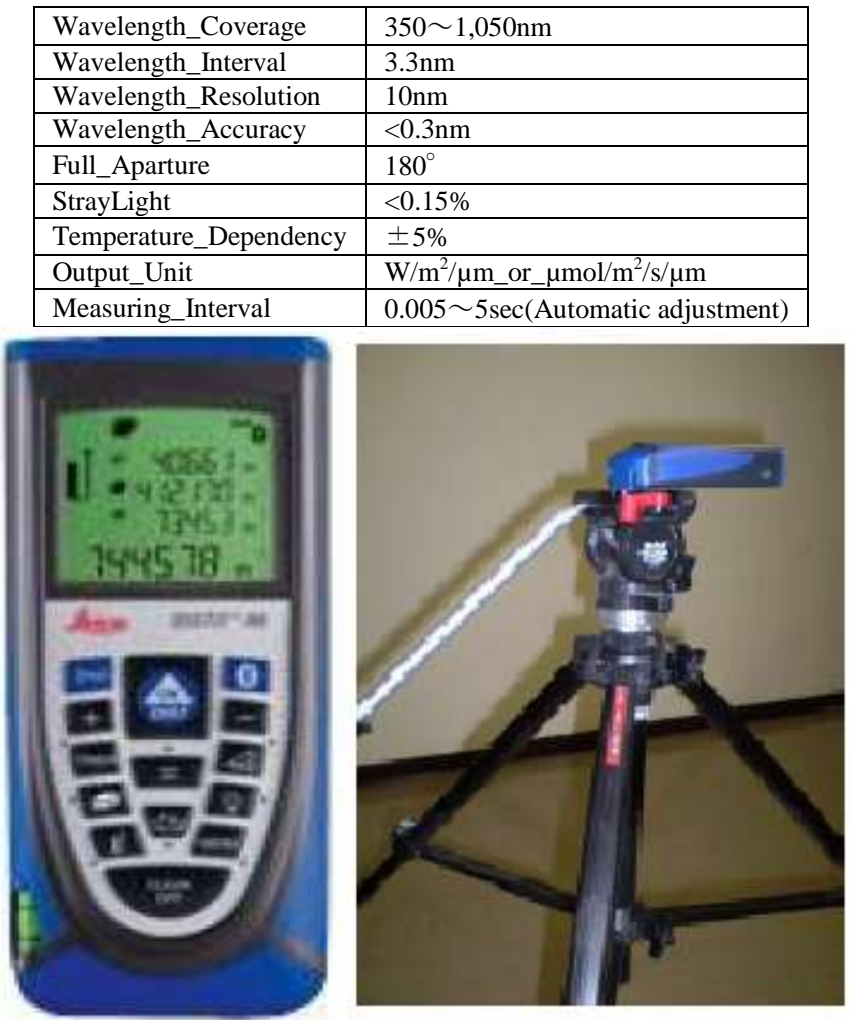

(a) Laser ranging instrument
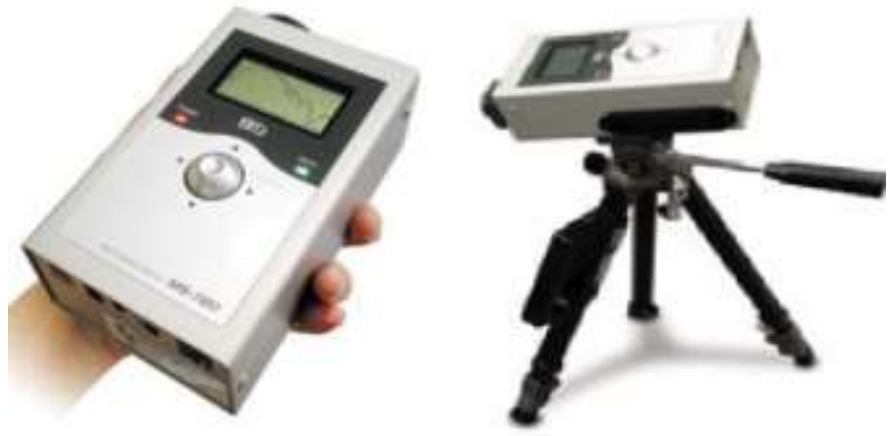

(b) Spectral radiometer

Fig. 9. Outlook of laser ranging instrument and spectral radiometer used for the preliminary experiment

Fig.10 (a) shows spectral response measured with the spectral radiometer under the rainy condition. The wavelength of the laser ranging instrument is $630 \mathrm{~nm}$.

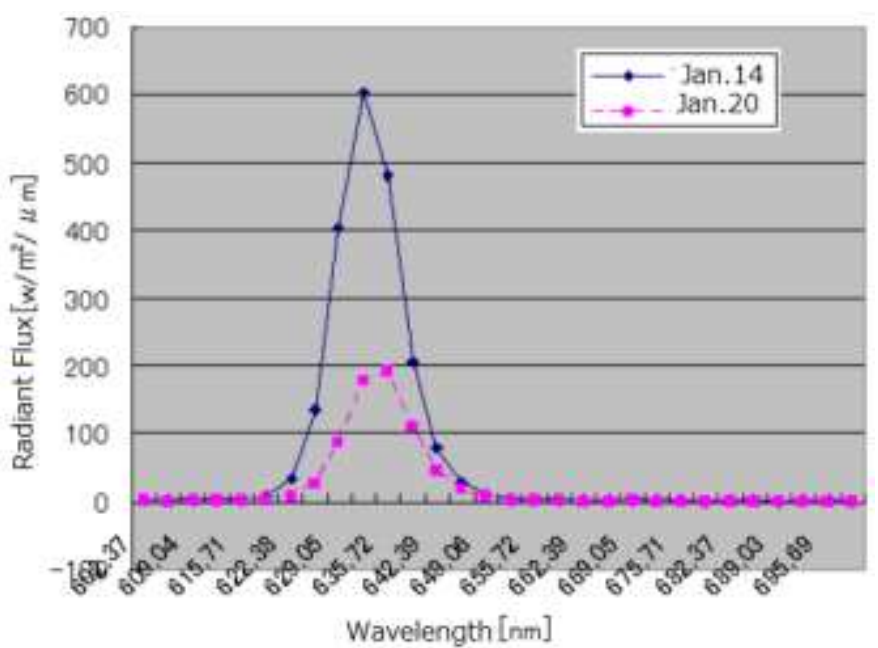

(a) Rainy condition in the nature

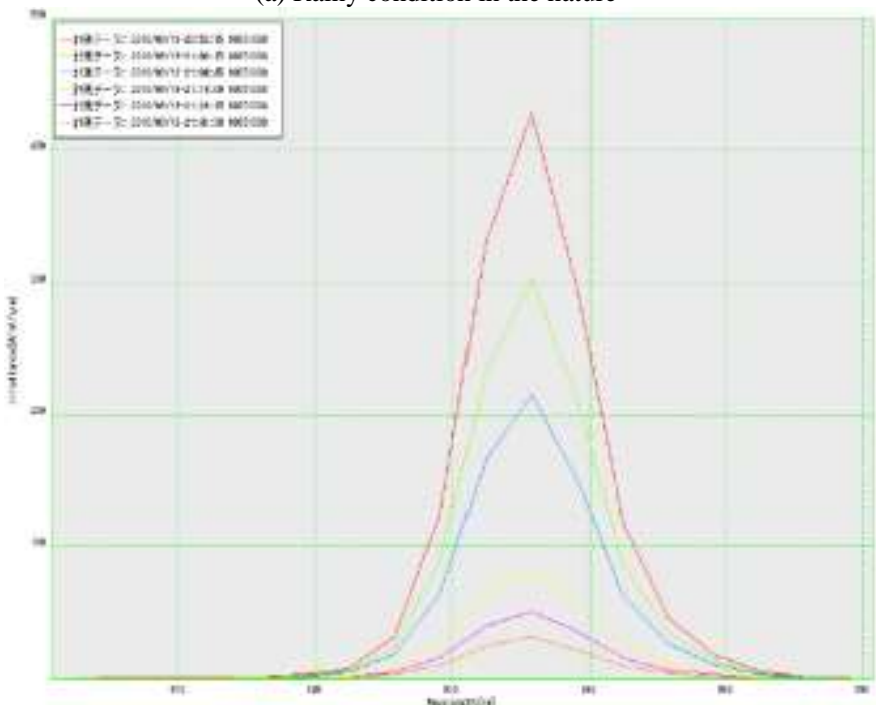

(b) Artificial rainy condition $(0,2.3,4.5,9,18,27 \mathrm{~mm} /$ houor $)$

Fig. 10. Spectral response of the laser ranging instrument

The preliminary experiment is conducted for no rainfall condition on January 14 and 20 in 2012. Meanwhile, Fig.10 (b) shows the spectral radiometer responses for artificial rainy condition of rainfall rate of $0,2.3,4.5,9,18$, and $27 \mathrm{~mm} /$ hour.

Therefore, there is peak at the laser wavelength.

On the other hand, Fig.11 shows the measured phase function. By changing the angle between laser light directions and pointing angle of the spectral radiometer, phase function can be measured as shown in Fig.12. 


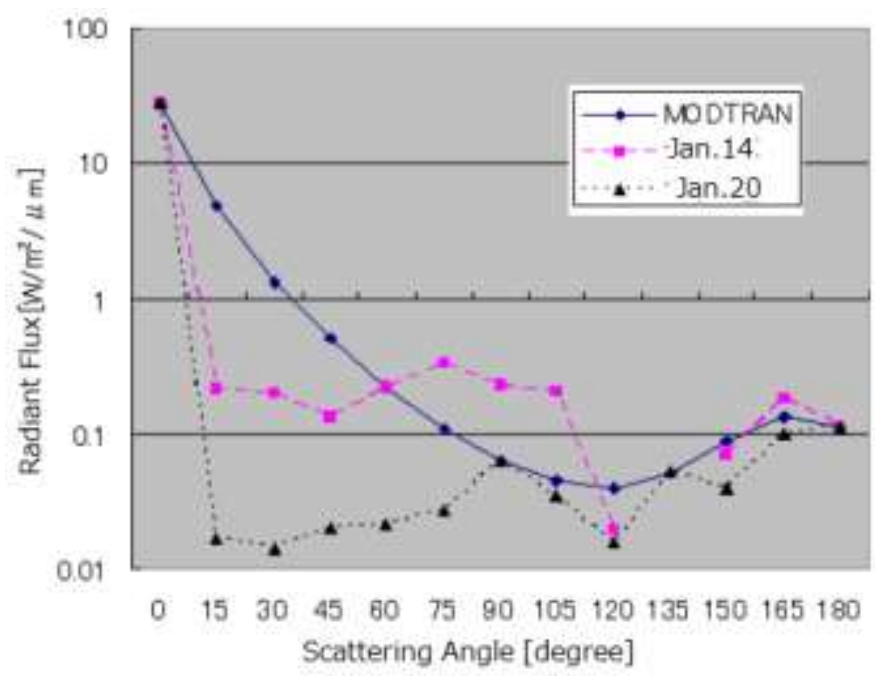

Fig. 11. Measured phase function

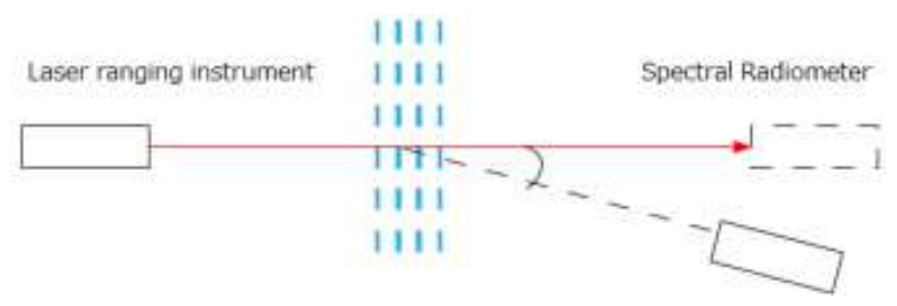

Fig. 12. Configuration of preliminary experiment (Phase function)

\section{B. Experiment for the Different Rainfall Conditions}

Experimental configuration is shown in Fig.13.

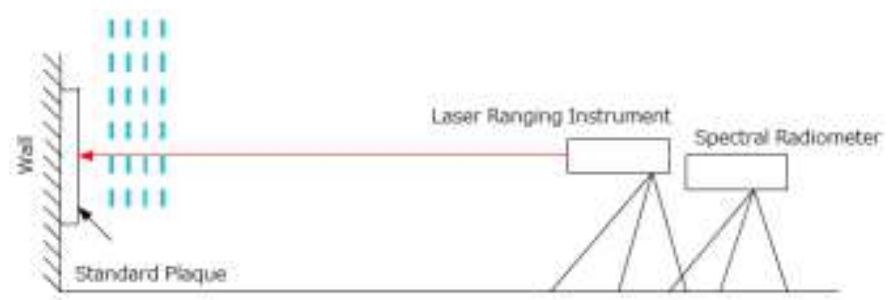

Fig. 13. Configuration of preliminary experiment

Fig.14 shows the measured spectral radiant flux of the scattered laser light from the back for no rainfall condition. Red line shows the radiant flux without laser light (noise component). Therefore, it is found that MS-720 of spectral radiometer is so noisy for the wavelength is over $900 \mathrm{~nm}$. On the other hand, blue and green lines show laser repetition cycle 1 and 3 seconds, respectively. There are some water vapor and $\mathrm{O}_{2}$ absorption lines in the Fig.14 of spectral radiant flux. Also, red laser light is not so dominant for the scattered light. Furthermore, 3 seconds repetition cycle response is a little bit greater than that for 1 second repetition cycle.

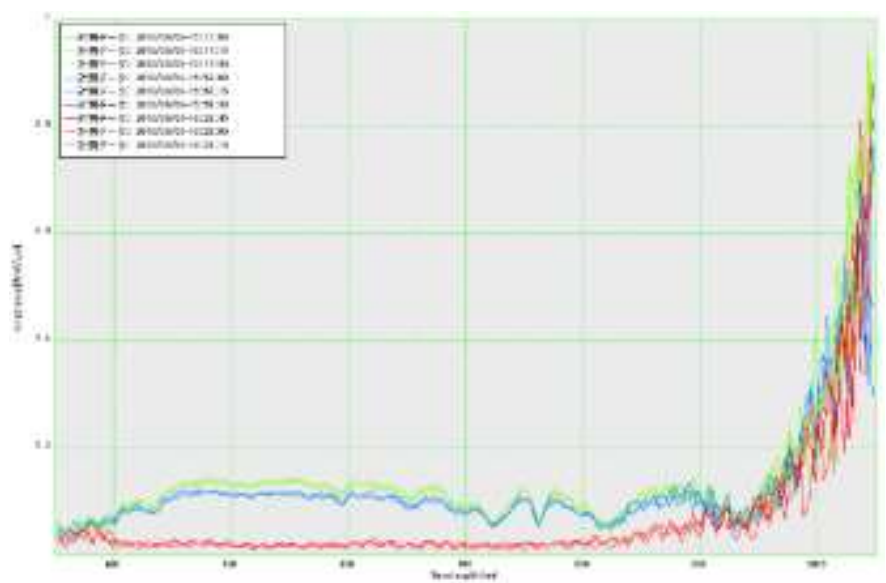

Fig. 14. Spectral radiant flux of the scattered laser light from the back for no rainfall condition

Fig.15 (a) shows the measured spectral radiant flux of the scattered laser light from the back for rainy condition. Rainfall rate for this case is $9 \mathrm{~mm} / \mathrm{hour}$. Red and green lines show laser repetition cycle 1 and 3 seconds, respectively. Through the comparison between Fig.14, it is found that the response for the $9 \mathrm{~mm} /$ hour of the rainfall rate is a little bit lower than that for no rainfall condition obviously. Meanwhile, Fig.15 (b) and (c) shows the measured spectral radiant flux of the scattered laser light from the back for rainy condition. Rainfall rate for this case is 18 and $27 \mathrm{~mm} /$ hour, respectively.. Red and green lines show laser repetition cycle 1 and 3 seconds, respectively. Through the comparison between Fig.14, it is found that the response for the 18 and $27 \mathrm{~mm} /$ hour of the rainfall rate is a little bit lower than that for no rainfall condition obviously.

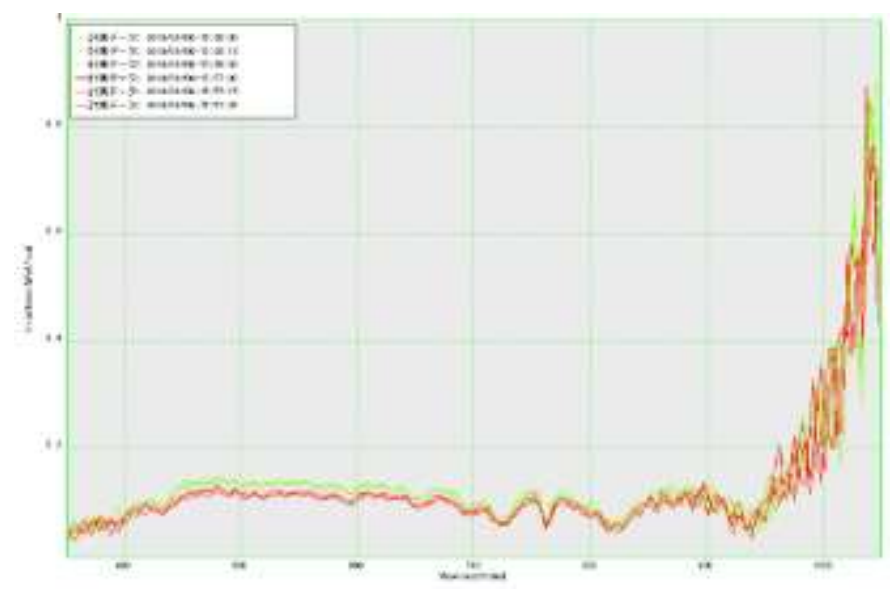

(a) $(9 \mathrm{~mm} / \mathrm{hour})$ 


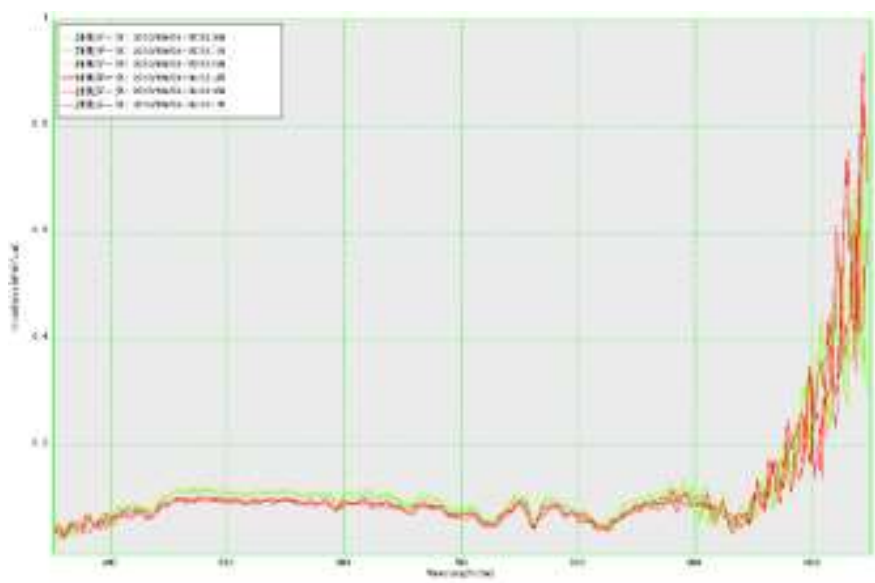

(b) $18 \mathrm{~mm} / \mathrm{hour}$

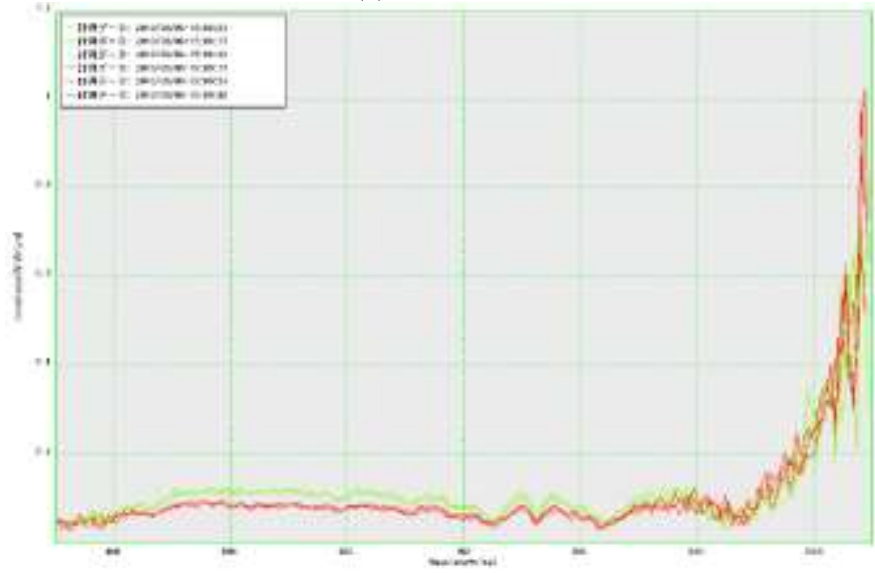

(c) $27 \mathrm{~mm} / \mathrm{hour}$

Fig. 15. Spectral radiant flux of the scattered laser light from the back for rainy condition

On the other hand, Fig.16 (a) and (b) shows the measured spectral radiant flux of the scattered laser light from the back for no rainy and rainy conditions. Laser repetition cycle is set at 1 second for Fig.16 (a) while that for Fig.16 (b) is set at 3 seconds, respectively. Red, green, blue and violet lines in Fig.16 show the cases of rainfall rate of $0,9,18$, and 27 $\mathrm{mm} /$ hour, respectively.

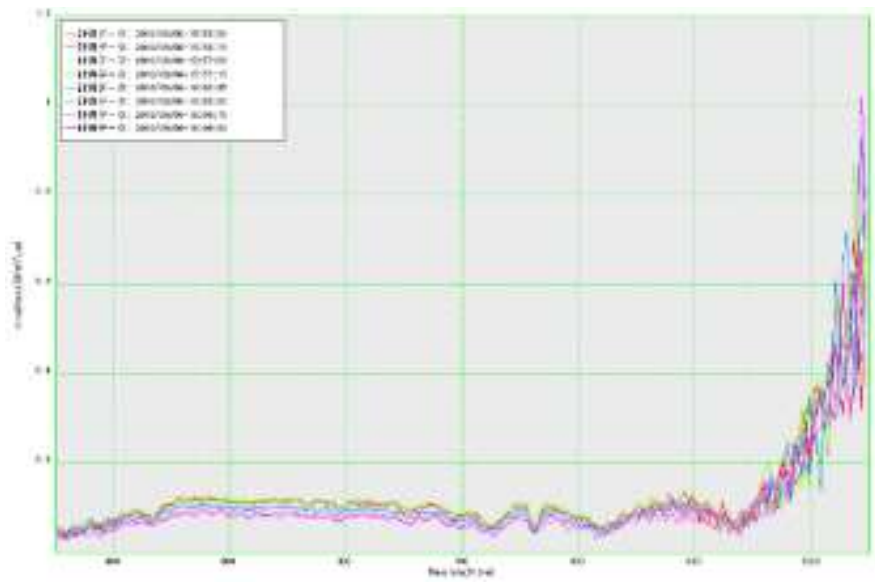

(a) 1 second

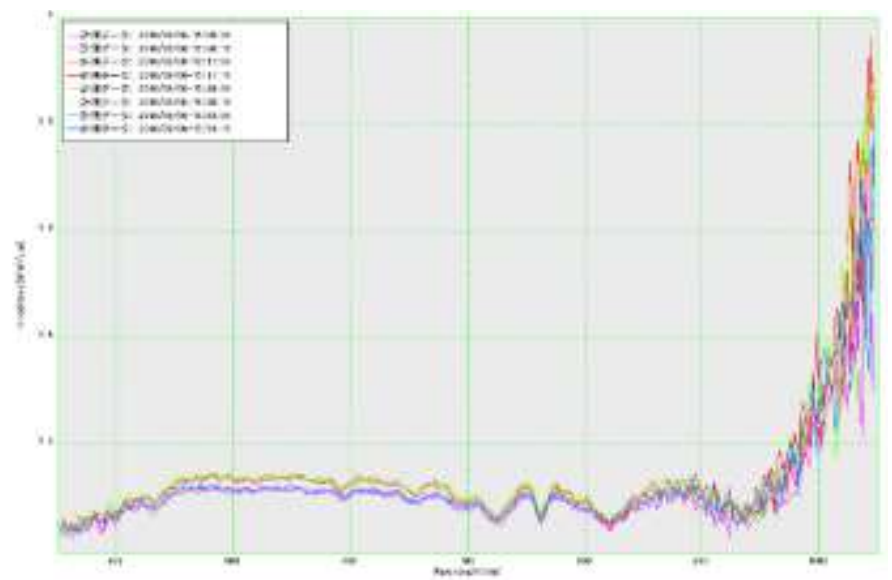

(b) 3 seconds

Fig. 16. Spectral radiant flux of the scattered laser light from the back for no rainfall and rainy conditions

It is confirmed that the repetition cycle of 3 seconds would be better to get much high sensitivity of the scattered laser light from rain droplets.

\section{CONCLUSION}

Methods for size distribution estimation and rainfall type discrimination with estimated phase function using measured reflected laser light by rain droplet are proposed. Preliminary experiments are conducted with Laser ranging instrument and spectral radiometer for estimation of size distribution and rainfall type discrimination as well as phase function of scattering by rain drops.

Through the experiments, it is found that rainfall type can be discriminated with the measured phase function using laser light scattered by rain droplets. Also, it is found that rain droplet size distribution can be estimated with the same measured phase function. Furthermore, rainfall rate is also estimated with the response of the scattered laser light by rain droplets.

Further investigation is highly required for the experiments in real situations. Also, relation between rainfall rate and land slide has to be clarified. Although the sensor network for landslide monitoring with laser ranging system avoiding rainfall influence on laser ranging by means of time diversity and satellite imagery data based landslide disaster relief is proposed already, rainfall rate estimation accuracy is not good enough.

\section{ACKNOWLEDGEMENTS}

Author would like to thank Mr. Kiyohito Kawasaki of former student of Saga University for his effort for conducting the experiments.

\section{REFERENCES}

[1] Dunnicliff, J. 1993. Geotechnical Instrumentation for Monitoring Field Performance. New York: John Wiley \& Sons

[2] Mikkelsen, P.E. 1996. Field instrumentation. In A.K. Turner \& R.L. Schuster (eds), Landslides: Investigation and Mitigation, Special Report 247: 278-316. Washington, DC: National Academy Press.

[3] Eyers, R., Moore, J. McM., Hervas, J. and Lui, J. G., 1995. Landslide mapping using digital imagery: a case history from south east Spain". 
Proc. 31st Annual Conf. on Geohazards and Engineering Geology, 379 388. 1995, Coventry, UK

[4] Wang, L. and He, D. C. "A new statistical approach for texture analysis". Photogrammetric Engineering and Remote Sensing, 56 (1), 61 $-66.1990$.

[5] Zhang, Z.; Gong, H.; Zhao, W.; Zhang, Y. 2005. AppLeication of remote sensing to study of landslides. IEEE, 1546-1549.

[6] Rosin, P.L. and Hervás, J. (2005). Remote sensing image thresholding methods to determining landslide activity. International Journal of Remote Sensing, 26, 6, 1075-1092

[7] Kohei Arai, Xing Ming Liang, Comparison of rainfall rate using TRMM satellite onboard PR data derived from Rayleigh and Mie scattering assumptions and Z-R relation assumption, Journal of Japan Society of Photogrammetry and Remote Sensing, 49, 2, 67-74, 2010

[8] Kohei Arai, Kenta Azuma, Rainfall rate estimation with AMSR data on board AQUA satellite taking into account geometric relation between the microwave radiometer and observation targets, Journal of Japan Society of Photogrammetry and Remote Sensing, 49, 1, 32-40, 2010

[9] K.Arai, Sensor network for landslide monitoring with laser ranging system avoiding rainfall influence on laser ranging by means of time diversity and satellite imagery data based landslide disaster relief, International Journal of Applied Sciences, 3, 1, 1-12, 2012.

[10] Kohei Arai, Comparison between Rayleigh and Mie scattering assumptions for Z-R relation and rainfall rate estimation with TRMM/PR data, International Journal of Advanced Research in Artificial Intelligence, 2, 8, 1-6, 2013.

[11] F.Yoshino, Radar Hydrology, MorikitaShuppan Publishing Co. Ltd, 2002.

[12] C. Mätzler, Drop-Size Distributions and Mie Computations for Rain,InstitutfürAngewandtePhysik, Research Report No. 2002-16, 2002
[13] C.W. Ulbrich, Natural Variations in the Analytical Form of the Raindrop Size Distribution, Journal of Applied Meteorology, 22(10), pp.17641775, 1983.

[14] U. Remko, Raindrop size distributions and radar reflectivity-rain rate relationships for radar hydrology, Hydrology and Earth System Sciences, 5(4), pp.615-627, 200

[15] L.J. Battan, Radar Observation of the Atmosphere, Univ. of Chicago Press, Chicago, Illinois, 324p., 1973.

\section{AUTHORS PROFILE}

Kohei Arai, He received BS, MS and PhD degrees in 1972, 1974 and 1982, respectively. He was with The Institute for Industrial Science and Technology of the University of Tokyo from April 1974 to December 1978 and also was with National Space Development Agency of Japan from January, 1979 to March, 1990. During from 1985 to 1987, he was with Canada Centre for Remote Sensing as a Post-Doctoral Fellow of National Science and Engineering Research Council of Canada. He moved to Saga University as a Professor in Department of Information Science on April 1990. He was a counselor for the Aeronautics and Space related to the Technology Committee of the Ministry of Science and Technology during from 1998 to 2000. He was a councilor of Saga University for 2002 and 2003. He also was an executive councilor for the Remote Sensing Society of Japan for 2003 to 2005. He is an Adjunct Professor of University of Arizona, USA since 1998. $\mathrm{He}$ also is Vice Chairman of the Commission-A of ICSU/COSPAR since 2008. He received Science and Engineering Award of the year 2014 from the minister of the ministry of Science Education of Japan and also received the Bset Paper Award of the year 2012 of IJACSA from Science and Information Organization: SAI. In 2016, he also received Vikram Sarabhai Medal of ICSU/COSPAR and also received 20 awards. He wrote 34 books and published 520 journal papers. He is Editor-in-Chief of International Journal of Advanced Computer Science and Applications as well as International Journal of Intelligent Systsems and Applications. http://teagis.ip.is.sagau.ac.jp/ 